\title{
Arts and Early Childhood collaborations: leaders' perceptions of the challenges and the opportunities
}

\author{
Wickett, Karen
}

http://hdl.handle.net/10026.1/15806

\subsection{0/09669760.2020.1778446}

International Journal of Early Years Education

Taylor \& Francis (Routledge)

All content in PEARL is protected by copyright law. Author manuscripts are made available in accordance with publisher policies. Please cite only the published version using the details provided on the item record or document. In the absence of an open licence (e.g. Creative Commons), permissions for further reuse of content should be sought from the publisher or author. 


\title{
Arts and Early Childhood collaborations: leaders' perceptions of the challenges and the opportunities
}

\author{
Karen Wickett
}

Plymouth Institute of Education, University of Plymouth, Plymouth, UK;

Email address: karen.wickett@plymouth.ac.uk

ORCHID: 0000-0003-2986-5078

This research was part of an arts and Early Childhood Education and Care (ECEC) collaboration, which placed three artists in three ECEC settings. The aim of the research was to create a 'meeting place' (Dahlberg and Lenz Taguchi 1994) for local Authority advisors, ECEC leaders and arts leaders, to explore their perceptions of the challenges and opportunities when establishing and developing an arts and ECEC collaboration. Ethical approval was granted by the University of Plymouth. Participants were informed of my dual role as researcher and as trustee of the arts organisation. Qualitative data were generated in two phases. During the first phase participants with similar roles met, identified what they viewed were the key challenges and opportunities when establishing the collaboration. The second phase provided a space for all participants to meet and discuss these and together identify actions for future practice, which could guide longer-term arts and ECEC collaborations. Implications for practice are for the organisation leaders to maintain a focus on building their partnership as well as constructing a shared vision of an arts and ECEC collaboration.

Keywords: The Arts, Early Childhood Education Care, collaborations, instructional partnership, administrative partnership

\section{Introduction}

The practice of having an artist as a member of the pedagogic team in the preschools of Reggio Emilia has inspired many arts and ECEC collaborations across the globe (Churchill- Dower 2009). Projects include Playlinks in Ontario, Canada (McLauchlan 2017); artist in residence programmes in the USA (Eckhoff 2009), Little Big Bang, England (Young 2012), and the Helsinki Arts Education Project, Finland 
(Nevanen et al. 2014). However, factors such as inconsistent funding for both sectors (Arts Council 2005), the focus on academic subjects (McLauchlan 2017) and uncertainty of the role of the artist when working in the ECEC setting (Petrie and Chambers 2010) have led to various models of how artists are involved in the ECEC setting and for how long (Remer 2010). Remer (2010) found that longer-term arts and education collaborations are more likely when leaders of arts organisations and education settings construct the polices and goals together.

This paper discusses research that was part of an arts and ECEC collaboration, where an artist specialising in either dance, the visual arts or digital arts was placed in an ECEC setting for up to 10 weeks. When designing the research process I aimed to create a 'meeting place' (Dahlberg and Lenz Taguchi 1994) where ECEC leaders, Local Authority (LA) advisors and the Early Years (EY) leaders of an arts organisation, could reflect on their experiences of being part of the arts and ECEC collaboration. The meeting place provided participants the opportunity to discuss the challenges and the opportunities when establishing and developing longer-term arts and ECEC collaborations. The reflective discussion led to participants identifying actions that they thought would minimise the challenges and strengthen the opportunities for longer-term arts and ECEC collaborations.

The research was funded by the EY service of an arts organisation based in South West, England. The arts organisation is a charity. Since 2000, the EY service has facilitated a range of opportunities for the under-fives and their families to enjoy the arts. Alongside these experiences, the EY team has collaborated with ECEC practitioners to provide arts experiences in ECEC settings. Collaborations included one off performances, short-term projects and a longer-term project; Little Big Bang, which involved an artist working in a Children's Centre with ECEC practitioners for two 
years. In this longer-term collaboration the artist became a member of the pedagogic team who planned the learning environment for children and their families (Young 2012). The ECEC setting that I was a practitioner and leader had been involved in several of these arts and ECEC collaborations including Little Big Bang. In 2010, a new government led to changes in the Children's Centre and arts organisation structures and funding. These changes are discussed next.

\section{A Change in government - changes in arts and ECEC collaborations}

In England, between 1997 and 2010, the Labour government expressed a commitment to an expansion of both the arts and ECEC sectors. The growth in the arts sector was motivated by the aspiration that Britain would be the "World's Creative Hub" (Roberts 2006, 8) and the vision for the ECEC sector was to provide 'pre-school provision for the under-fives and childcare available to all' (Brown 2004).

Consequently, there was significant government funding and strategic planning for both sectors. The government's vision of a global creative hub was reflected in both the Curriculum Guidance for the Early Years Foundation Stage (DfEE 2000) and the Early Years Foundation Stage framework (DCSF 2008); creative development was one of the six areas of learning and development. In both documents, providing children with 'opportunities to work alongside artists and other creative adults' (DfEE 2000, 117; DCSF 2008, 106) was viewed as good practice (Arts Council 2005). During this period numerous arts organisations and ECEC settings collaborations flourished (Young 2016).

The change of government, in 2010, led to a period of austerity, which resulted in a reduction in arts funding and redistribution of ECEC funding. Some ECEC provision (Children's Centres) closed and school leaders were encouraged to provide provision for younger children in schools (DfE 2013). There was also a change in 
government's perception of the purpose of the ECEC sector. In 2012 ECEC

practitioners were expected to promote 'teaching and learning to ensure children's 'school readiness'” (DfE 2012, 2). Changes in the EYFS (DfE 2012; DfE 2017) included creative development (DCSF 2008) becoming 'Expressive Arts and Design' (DfE 2017) and the introduction of the 'Characteristics of Effective Learning' (CoEL). These are 'playing and exploring', 'active learning' and 'creating and thinking critically' (DfE 2017, 7). Whilst there is not an explicit reference to creative development in the EYFS (DfE 2017) qualities of creativity are reflected in the CoEL (DfE 2017). The CoEL (DfE 2017) 'creating and thinking critically' specifies that children should 'have and develop their own ideas, make links between ideas, and develop strategies for doing things' (DfE 2017, 10). Despite the expectation to foster children's disposition to be creative, the emphasis on the preparation of children for school learning can lead to a narrowing of the curriculum resulting in children's creative development being overlooked (Chappell et al. 2016).

\section{An Arts and ECEC collaboration continuum}

In the 1960s, Malaguzzi the founder of the pre-schools of Reggio Emilia, Italy introduced an atelierista (a person trained in the arts) to the pedagogic team (Gandini 2012). The addition to the pedagogic team was reflected in the physical environment, as an atelier (a studio) was included in the design of the pre-school building (Gandini 2012). Although the practices of Reggio Emilia have inspired arts and ECEC collaborations across the globe, what these look like in different contexts has led to 'an instructional potpourri' (Remer 2010,82) of collaborations. These can be placed on a continuum. Depending how long the collaboration lasts and how the artist works with 
the ECEC practitioners will influence where an arts and ECEC collaboration is placed. For instance, at one end of the continuum, the artist is a permanent member of the pedagogical team and at the other the artist is an entertainer (McLauchlan 2017, 139). The former type of collaboration is when the artist engages with the ECEC practitioners in the processes of reflective practice and the co-construction of the learning environment, pedagogic practices and the curriculum. In the latter collaboration, the artist delivers an activity such as a one off show and then leaves the ECEC setting. Gattenhof and Radvan $(2009,214)$ described this as a 'drop in and drop out' collaboration. In the drop in and drop out collaboration there will be limited opportunities for the ECEC practitioner and artist to reflect and plan the arts activity together.

\section{An arts and ECEC collaboration comprises of two partnerships}

The discussion above mainly refers to the partnership between those that work with the children. However, Remer (1996) cited two partnerships in an arts and education collaboration; the 'instructional partnership' and the 'administrative partnership' (Remer 1996). Each partnership has a different role in the collaboration. Those in the instructional partnership are those that work with the children; usually the artist and ECEC practitioner and those in the administrative partnership are leaders of the arts and ECEC organisations. As discussed above the focus of those with an instructional partnership is to plan the 'content and methodology of the curriculum' (Remer 1996, 114). Those in the administrative partnership focus on the 'organization, design, co-ordination, governance, overall roles and responsibilities and evaluation of the program effectiveness' (Remer 1996, 114). Although the partnerships have been 
discussed as two distinct roles, in practice the roles and partnerships are likely to be entwined and will change as the arts and ECEC collaboration evolves (Remer 1996).

A key influence of what the arts and ECEC collaboration looks like in practice and where the collaboration is situated on the arts and ECEC continuum is how the ECEC leader values and views the arts (McLauchlan 2017). In the 'drop in and drop out' arts and ECEC collaboration, the ECEC leaders tend to view the arts activity as a commodity to be purchased from the arts organisation (Remer 1996). It is the role of the arts organisation to produce an activity to be purchased and the role of the ECEC leader is to purchase the activity. If on the other hand the ECEC leader believes that an arts and ECEC collaboration has a positive influence on the learning environment for children and adults (Vermeersh and Vandenbroucke 2013) they will aspire to create long-term arts and ECEC collaborations with the arts organisation leaders. This partnership is based upon mutual trust and respect, where each partner acknowledges what the other brings to the collaboration (Remer 1996).

Long-term projects do not necessarily lead to lasting arts and ECEC collaborations (Nevanen et al. 2014; Remer 2010). Remer (2010) suggests long-term arts and ECEC collaborations are more likely when those with an administrative partnership share their beliefs and construct policies and goals for an arts and ECEC collaboration. Leaders of both organisations are also required to be open to learning (Remer 1996), to be flexible to innovate, create networks, and foster their partnership (Roberts 2006). In such a collaboration those within the administrative partnership can even influence national arts and ECEC policies (Remer 2010). 


\section{Research context and questions}

Soon after the change in government in 2010 the arts organisation's funding from the Local Authority ceased and ECEC (Children Centre) leaders left or changed roles. These changes led to many of the arts organisations' ECEC collaborations, that had flourished during the period of growth, ending. In 2012 my role, as Children's Centre leader/practitioner also ended. I left the Children's Centre and became a full time university lecturer. When I left my Children's Centre role the arts organisation invited me to join the organisation's board of trustees. I accepted.

After a period of limited funding, in 2016 the arts organisation leaders secured funding from The Paul Hamlyn Foundation (PHF) to fund the ECEC and arts collaboration; 'Elements'.

Elements comprised of:

- $\quad$ six ECEC settings and three artists. The artists were specialists in either dance, the visual arts or digital arts;

- $\quad$ an artist working with and alongside ECEC practitioners for six sessions in each setting;

- $\quad$ a Local Authority (LA) advisor who acted as a pedagogical mentor;

- beginning, mid-term and end reflection sessions for artists, ECEC practitioner, arts organisation leaders and LA advisors

- $\quad$ at the beginning of the project ECEC practitioners and artist identified a pedagogical question. Together they explored and answered the question;

- two free places on Professional Development sessions were provided for ECEC practitioners;

- this research. 
In light of the demise of previous arts and ECEC collaborations the arts organisation Early Years (EY) leader and I wanted to explore ECEC leaders' understandings of longer-term arts and ECEC collaborations. This led to the research questions:

- What do those in an administrative partnership, ECEC leaders, LA advisors and the arts organisation EY leaders, believe are the challenges and opportunities around developing long-term arts and ECEC collaborations?

- What do they believe can minimise the challenges and enhance the opportunities for longer-term arts and ECEC collaborations?

\section{Research design and methods}

When designing this piece of interpretative research I was guided by the belief that the participants are not subjects to be explored but are participants to learn with (Cornwall and Jewkes 1995) and that research is a tool to facilitate my and participants' learning. When designing the research I drew on the concept of a 'meeting place' (Dahlberg and Lenz Taguchi 1994). A meeting place is not just a physical space for people to meet but also a philosophical space where they share experiences and understandings, reflect and co-construct understandings and practices (Dahlberg 2013). In this study the arts organisation leaders, the ECEC settings leaders and the LA advisors shared their views and experiences of being part of an Arts and ECEC collaboration and considered the practices that they believed would foster longer-term collaborations. My role in the research process was not only to learn about their views and experiences, but also to facilitate the discussion so that all participants could be heard. 
A challenge, when creating a meeting place, is that the knowledge held by some groups is valued more than others, and this can lead to those that perceive themselves as having less power being silenced (Blumer 1969). To work towards all participants being heard the meeting place comprised of two phases. Data were generated during both phases. Phase one, comprised of three focus groups. Each focus group included participants who shared the same role. Phase two, comprised of a single focus group in which all participants came together. The first phase provided participants the space and time to explore ideas and articulate these in a group of people with a similar role. To guide these conversations I drew upon Lewin's (1943) force field theories. Although, Lewin's force field theory is a conceptual tool to gain insights into individual and group behaviour and change (Swanson, and Creed 2014), in this research force field theory provided a useful framework for the focus group discussions. Participants documented the challenges and opportunities that emerged during their discussion on the framework. They also considered and documented what were the strength of the challenges and opportunities for them.

Participants' documentation provided a guide for them during the second phase of the research. During this phase participants shared, with others in the administrative partnership, the challenges and opportunities around establishing and developing an arts and ECEC collaboration, which they had recorded during the first focus group. As facilitator of the research process, I noted and recorded the recurring challenges and opportunities. I shared these with participants. Participants then engaged in a reflective discussion, which led to them considering how the challenges could be minimised and the opportunities strengthened. Together they created five action points for practice, which they believed would develop opportunities for longer-term arts and 
ECEC collaborations. All focus groups discussions were audio-recorded and transcribed.

Each focus group lasted between 1.5 and 2 hours. The ECEC leaders and the final focus group were conducted in a hired room in the local theatre and arts centre. Due to the LA leaders' work commitments, their focus group was conducted at an office in County Hall and the arts organisation leaders met at my workplace.

Table 1. Research participants.

There were two EY Art Organisation Leaders, three Local Authority (LO) advisors and three ECEC leaders. Both EY arts organisation Leaders attended both focus groups. Stephanie the LA advisor also attended both focus groups but her colleagues were only able to one; Doris attended the first and Megan the second. Florence the ECEC leader attended both focus groups and Margaret and Lea (ECEC deputy) attended one each.

\section{Ethical implications}

Ethical decisions were made in line with guidelines from the University of Plymouth (UoP) and the ethical protocol agreed by the Plymouth Institute of Education Ethics Committee. It was explained that I had a dual role. I was the researcher from the UoP and also a member of the arts organisation board. It was decided to create a distinction in my roles I would contact and forward the information sheet and consent forms to participants and not visit the settings whilst the artist was at the setting. I 
forwarded the research paperwork a week before the focus group, providing time for participants to contact me and ask any questions about my dual role. There was further opportunity for participants to ask questions about the research and my role before the focus group started.

\section{Data Analysis}

Data analysis began during the second focus group. When each group fed back, recurring themes emerged. These included funding, the Early Years Foundation Stage (DfE 2017), a culture of learning, understandings of creativity and the arts and what an arts and ECEC collaboration looks like in practice. The discussions highlighted that what one group found challenging another group could view as an opportunity. Participants discussed and constructed five actions for practice that they thought would foster longer-term arts and ECEC collaborations. Following the discussions, I continued to explore the themes identified by the participants by analysing and comparing the data generated during both phases of the research. The findings are now presented.

\section{Findings}

\section{Key challenges when developing an arts and ECEC collaboration}

\section{Funding}

The reductions in government arts funding and redistribution of ECEC funding were not the only challenges for the arts organisation leaders; other challenges included the expectations of the funders and the consequences of these expectations. Rita and Delphine explain: 
When we write our funding bids, we are always having to compromise our projects, ..... we can only work with the vulnerable, certain people and certain communities. I think the [ECEC] partners, we have to work with can be unsupportive, they are not interested. (Rita arts organisation leader Focus Group (FG) 1a)

Because they [ECEC leaders/practitioners] are in hard press circumstances (Delphine arts organisation leader FG 1a)

The PHF aims to reduce the inequalities in society through the arts (Paul Hamlyn Foundation 2018). For leaders of ECEC settings situated in an area of disadvantage, the 'hard pressed circumstances' are likely to be multifaceted. If the leader is herself from the community where the ECEC setting is situated then she may also personally experience these. Professionally, the changes to ECEC policy and funding are also likely to contribute to the 'hard pressed circumstances' that the ECEC leader is experiencing.

The funders' expectations posed challenges when writing a funding bid, but so did the ECEC leaders' perceptions of the process of applying for funding.

I never do them [funding applications],...... Why beg for money? That's what's it is like (Margaret ECEC leader FG2)

Margaret is the leader of a private ECEC setting. The service she provides is likely to be funded by a mixture of government funding and fees paid by parents. These funding sources cover the costs of the ECEC provision. The arts organisation, however, is a charity and its leaders rely on money from grant-funding foundations and trusts to develop their arts provision. Writing bids for funding is a requirement of the arts 
organisation leaders' roles. Which sector the leaders come from will influence how they view writing bids and their role in the process.

\section{The Early Years Foundation Stage Framework (DfE 2017)}

The expectations of the EYFS (DfE 2017) posed challenges for the leaders when supporting arts and ECEC collaborations.

We [Megan and Rebecca] spoke about school readiness .... and the structure of the day. [The children were] unable to get enough time to ..... go with the artist (Megan LA advisor FG2)

After a couple of weeks everybody got together and it worked out just fine, [but]... I do feel that I'm under pressure to put more reception class values..[into our setting] (Florence ECEC leader FG2)

Megan had been supporting a reception class teacher. At the end of the reception class children move from an environment guided by the play based EYFS (DfE 2017) to the year 1 class which follows the expectations of the Key Stage 1 National Curriculum. Further down the 'epistemological hierarchy' (Urban 2008, 141), the expectation for Florence and her team to prepare children for the reception class is still apparent but they are able to work with the artist. These comments suggest that the closer the children are to the curriculum transition there are greater challenges faced by ECEC practitioners when fostering the arts and ECEC collaboration.

Whilst Florence referred to pressure from the school to prepare children for the next phase of their education Margaret made no explicit reference to these expectations. Florence leads a voluntarily run ECEC setting, which is located on a school site and 
Margaret is the leader of a small private early years setting, which is located in a residential area of a town. Not only is collaboration influenced by where the children are in the 'epistemological hierarchy' (Urban 2008) but also, this study suggests, by the geographical and socioeconomic location of the ECEC setting.

\section{Different definitions of creativity}

Leaders of all the organisations explained that they struggled to define creativity as they each held a different definition of the concept. Florence's and Rita's comments reflect the leaders' beliefs.

Different understandings of creativity and the arts, perhaps they have changed a little bit now (Florence ECEC leader FG2)

[We] struggled with shared understanding, quality early years creativity. (Rita arts organisation EY leader FG2)

Creativity is a complex term to define (NACCE 2001; Nutbrown 2013).

Understandings of creativity range from an innate creative talent, which some are born with (NACCCE 2001) to viewing creativity as a 'quality of human thinking' (Rinaldi 2006, 102). From the first perspective, those born with the innate creative talent will produce a great piece of art, an invention or knowledge. Whereas, when creativity is viewed as a quality of human thinking children and adults have the potential to be creative during everyday activities (Nutbrown 2013). Thus, being creative is when children and adults are thinking imaginatively and making links between experiences, objects and ideas to create something new (Rinaldi 2006; NACCCE 2001). Features of creativity are key to 'possibility thinking' (Craft 2002), which involves: posing 
questions, play, making connections, being imaginative, innovation, risk taking and self-determination (Burnard et al. 2006).

In the current EYFS (DfE 2017) it is an expectation that practitioners will notice how children make links between existing understandings to create new understandings. Despite qualities of creativity, featuring in the CoEL of the EYFS (DfE 2017) Doris' comment suggests that the removal of the area of learning, 'creative development' has led to a narrowing of the curriculum.

.... we have lost elements of that creativity from the curriculum. (Doris LA advisor FG 1b)

The narrowing of the curriculum could also explain Rita's concern that there is not a shared understanding of 'early years creativity'. Her comment also suggests that creativity in the early years context has a distinct definition.

Further complexity when defining creativity is it is often associated with the arts. Florence hints to this difficulty when referring to 'creativity and the arts'. Whilst the arts foster children's creativity, the qualities of creativity are much broader and support children's learning in all areas of learning and development in the EYFS (Nutbrown 2013).

\section{Perceptions of the arts}

During their life course ECEC leaders and practitioners have constructed their beliefs about the arts and their involvement with the arts (Griffin 2017). Delphine shared an observation, which suggests that the ECEC practitioners were not confident when entering an arts organisation: 
They [the ECEC practitioners] came [to the art gallery] they didn't know what art was, they were very intimidated (Delphine arts organisation leader FG 1a)

If ECEC leaders and practitioners have had few opportunities to experience the arts they may perceive themselves as not being endowed with a creative talent (Griffen 2017) and unfamiliar of the expectations when participating in arts activities. Thus they are less confident when planning arts activities and experiences for the children and their families, in and beyond the ECEC setting.

This could further explain Delphine's and Rita's earlier comments when they described the ECEC leaders as being 'not interested' and 'unsupportive' when establishing an arts and ECEC collaboration. Instead of being 'not interested' and 'unsupportive' the ECEC leaders may not only be uncertain of their professional role in an arts and ECEC collaboration, but they may also be unfamiliar and uncertain how to participate in the arts activities planned during the collaboration. The 'hard pressed circumstances' that Delphine mentioned could contribute to this uncertainty. Financial constraints could limit the opportunities for ECEC leaders to access, experience and become familiar with the arts beyond work.

\section{What arts and education collaborations look like in practice.}

Not only did the leaders hold different understandings of creativity and the arts, they also had different views of what an arts and ECEC collaboration might look like in practice. 
We struggled with a shared understanding of [what] a quality early years collaboration [looks like in practice]. I think an artist works best when they are viewed as a member of that team. I think they have to be there in the morning, every single day as an artist in residence (Rita arts organisation EY leader FG2)

Now the practitioners are confident enough to talk to their artist and stay in contact with them, via email and phone, now that we have had access to them. (Margaret ECEC leader FG2).

Rita's and Margaret's understandings of arts and ECEC collaborations look different in practice. Rita's vision suggests a longer-term collaboration, as the artist is a permanent member of the pedagogic team. Together the artist and ECEC practitioners plan the learning environment. Whereas, Margaret explained that the short-term arts and ECEC collaboration had enabled the ECEC practitioners and artist to maintain their instructional partnership by communicating via email and telephone. These interactions between artist and ECEC practitioners are likely to be ad hoc.

Participants referred to the instructional partnership (Remer 1996) but no participant made reference to fostering their administrative partnership (Remer 1996). This suggests that maintaining the focus on the pedagogical approaches, which is the role of those in the instructional partnership, can distract attention from the partnership between leaders.

\section{Key opportunities when developing an arts and ECEC collaboration}

Whilst funding and the EYFS (DfE 2017) presented challenges for administrative partnerships, they could also provide opportunities to foster administrative partnerships and to develop longer-term arts and ECEC collaborations. 


\section{Funding}

Despite sources of funding shrinking, Delphine had been successful in sourcing funding which enabled various arts and ECEC collaborations:

...we have a lot of successful funding bids..... Whilst the funding from central government falls away we are just glad that we seem to be doing something right. (Delphine arts organisation EY leader FG2)

During the phase of adjusting to the reduction in government arts funding, Delphine and her colleagues remained flexible and responded by identifying other funding partners.

\section{The Early Years Foundation Stage (DfE 2017)}

The collaboration enabled Lea to notice the children's learning and make links with the expectations of the EYFS (DfE 2017) that Stephanie believed are often overlooked:

I am learning a lot more about the characteristics of effective learning. I never paid as much attention to that as I think I should have. For example, like the senses, some children were more interested in the sounds and some children the touch ..... some children liked the feel of the small objects. (Lea representing ECEC leader FG 1C)

If we focus more on the characteristics of effective learning. Because it is all about how the children learn. So it's about building on that really. (Stephanie LA advisor FG2)

The CoEL (DfE 2017) focuses on how children learn, which reflects many of the qualities of creativity. Stephanie's and Lea's comments suggest that the 
Characteristics of Effective Learning (DfE 2017) provide a shared language for artists and ECEC practitioners to notice and foster children's learning. The CoEL (DfE 2017) are a useful tool for ECEC practitioners and artists, as there is a sense of familiarity for both groups.

There are inconsistencies and contradictions (Ball and Bone 1992) in the EYFS (DfE 2017) which can offer possibilities for an arts and ECEC collaboration to flourish. Whilst on one other hand, the EYFS (DfE 2017) requires ECEC practitioners to foster children's CoEL (DfE 2017), on the other they are expected to ensure children are ready for school (DfE 2017). The former focuses on fostering children's dispositions and attitudes to learning and the latter focuses on teaching children the skills, knowledge and behaviours for formal school learning, which are generally associated with literacy and numeracy. A role for those in the administrative partnership is to identify the inconsistencies and contradictions when interpreting the EYFS (DfE 2017) and focus on the aspects of the framework, such as the CoEL (DfE 2017), that will enable the collaboration to flourish and grow.

\section{Supportive collaborations}

Stephanie suggests that supportive networks beyond the setting can enhance

ECEC leaders' and practitioners' confidence to challenge.

It's finding that network of people that think similar to give you confidence to challenge. Sometimes it's difficult and people feel they shouldn't be disloyal and go outside of their organisation to find these people (Stephanie LA advisor FG2)

I think you said peer to peer network has really helped ...the cluster groups (Delphine arts organisation leader FG2) 
The cluster groups that Delphine refers to are meetings attended by ECEC leaders and practitioners, who generally have similar roles. However, if the administrative partnership comprises people with a diverse range of roles, they can challenge the dominant discourses from different perspectives (Remer 2010). An administrative partnership can include other ECEC leaders, funders, parents, local politicians and other advocates for arts and ECEC collaborations. A diverse group of people in the administrative partnership can create momentum for change not only in an ECEC setting, but also in the local community and beyond (Remer 2010)

\section{A culture of learning}

Florence and Stephanie explain that being a part of the arts and ECEC

collaboration provided an opportunity for everyone to learn.

Practitioner confidence coming away with different ideas, different understanding of creativity and art. I think even though our artist brought a lot to us, but we were also able to talk to him about the process and not the outcome ..... (Florence ECEC leader FG1c)

I think, all of us have learnt a great deal through the project.... it's showing the awareness you are watching and observing you are not directing or controlling children's play [learning]. It's about actually facilitating it. (Stephanie LA advisor FG2)

Building on previous learning from other arts and ECEC collaborations, the arts organisation leaders designed the Elements arts and ECEC collaboration to include strategies that embedded reflective practice. Delphine and Rita were aware these projects not only focused on children's learning but also facilitated ECEC practitioners' learning about the arts and creativity. Strategies to support this learning included the 
role of the LA advisor - as a pedagogical mentor - and the planning sessions for artists, ECEC practitioners, pedagogic mentor and arts organisation leaders at the beginning, mid-point and end of the collaboration.

The learning discussed by participants focuses primarily on the pedagogic methodology, which is generally associated with the instructional partnership. No leader made explicit reference to their learning at a strategic level. However, the research did provide a 'meeting place' for leaders to reflect, consider and articulate their views of the challenges and opportunities when establishing and developing longer-term arts and ECEC collaborations. They highlighted five actions, which they believed would foster a longer-term arts and ECEC collaboration. These are for leaders to:

- $\quad$ be advocates for young children and the arts;

- construct a shared understanding of creativity, the arts and vision of an arts/ECEC collaboration;

- consider and articulate a shared understanding of funding, the funding application process and their roles in the application process;

- maintain a culture of can do and reflective practice;

- foster relationships and partnerships between each other and invite others, who are passionate about children, the arts and creativity to join the collaboration.

\section{Discussion}

Elements, the arts and ECEC collaboration, provided an opportunity for ECEC leaders and LA advisors to learn how working with an artist and arts organisation supports them and the ECEC practitioners to develop the pedagogic practices in their settings. The research design provided a meeting place for those in an administrative partnership to consider the challenges and opportunities around fostering longer-term 
arts and ECEC collaboration. This discussion primarily focused on ECEC practitioners' learning, the pedagogic practices and the relationship between the ECEC practitioners and the artist.

Findings of this research suggest that leaders of organisations in an arts and ECEC collaboration can overlook their administrative partnership. For longer-term arts and ECEC collaborations leaders are also required to foster their administrative partnership (Remer 1996). Consequently, when planning for an arts and ECEC collaboration, time and space are required for leaders to foster their relationships and administrative partnership. Constructing their vision of what an arts and ECEC collaboration looks like in practice, their beliefs about the arts and creativity will support the process of fostering relationships and administrative partnership. The time required to reflect and co-construct a vision and beliefs will depend on ECEC leaders' experiences of the arts and how they view the arts. For those with fewer experiences or negative perceptions of the arts, more time will be required, as they will need to change their understandings and perceptions of the arts and their involvement in the arts.

Delphine's, Rita's and my experiences of how changes in government's funding and ideologies can influence the longevity of an arts and ECEC collaboration also suggests that the administrative leaders keep an eye on changes at national government level. It is generally held that when ECEC practitioners' work is underpinned by principles, and supported by academic research evidence, their practice is less likely to be compromised by the expectations of local and national education policies (Edgington 2004). Drawing on their vision and beliefs those in the administrative partnership should also articulate their principles. Guided by these principles and noticing what is happening beyond their immediate context, those in the administrative partnership, can 
interpret and mediate these changes to maximise the opportunities and limit the detrimental influences on the collaboration.

\section{Conclusion}

This paper is underpinned by the belief that an arts and ECEC collaboration has a positive influence on the ECEC learning environment for children and adults alike (Vermeersh and Vandenbroucke 2013), but often these collaborations are not long-term or consistent across the ECEC sector. The paper has drawn on literature which suggests that an arts and ECEC collaboration consists of two partnerships; the instructional partnership (artists and ECEC practitioners) and the administrative partnership (leaders of organisations) (Remer 1996) and that longer-term arts and ECEC collaborations are more likely when those in an administrative partnership construct shared goals and policies (Remer 2010) . The research process did provide the leaders with a meeting place to co-construct beliefs, understandings and build their relationships and administrative partnership. However, the focus of the discussion was on children's learning, pedagogic practices and the relationships between those working with the children. An implication for leaders of arts organisations and ECEC settings is, when developing an arts and ECEC collaboration time and space must be created for those in both the instructional partnership and administrative partnership to foster their relationships. Part of this process is for those in an administrative partnership to construct a shared vision of what an arts and ECEC collaboration looks like in practice and the principles that will guide them in the venture of working towards the vision. Leaders are also required to be observant in noticing emerging changes beyond the immediate context. Guided by their shared vision and principles they will be more able to maximise the opportunities or minimise the detrimental influences of these changes 
on the arts and ECEC collaboration. This is of relevance to those in an administrative partnership who aspire to create longer-term arts and ECEC collaboration.

The arts and ECEC collaboration that participants were involved ended after the second focus group. Consequently, a limitation of this research is the short-term nature of the project, which meant that there was no time to explore how the administrative partnership evolved as participants put their actions into practice. Further research is required to explore how an administrative partnership evolves during a longer-term arts and ECEC collaboration, and how those in the administrative partnership manage changes in and beyond the collaboration.

This research was funded by the Take Art Ltd.

\section{References}

Arts Council England. 2005. Reflect and Review: the arts and creativity in early years London: Arts Council England

Ball, Stephen. J, and Richard Bowe. 1992. Subject departments and the 'implementation' of national curriculum policy: an overview of the issues. Journal of Curriculum Studies 24(2): 97 - 115. doi: 10.1080/0022027920240201

Blumer, Herbert. 1969. Symbolic Interactionism: Perspectives and Method. Engleswood: New Jersey: Prentice Hall 
Brown, Gordon. Chancellor of the Exchequer. 2004. Comprehensive Spending Review. Accessed January 3, 2012 http://news.bbc.co.uk/1/hi/uk_politics/3887877.stm.

Bryman, Alan. 2012. Social Research Methods. Oxford University Press: Oxford. Burnes, Bernard and Bill Cook. 2013. 'Kurt Lewin's Field Theory: A Review and Reevaluation'. International Journal of Management Reviews, 15 (4), pp. 408-425. doi: $10.1111 / \mathrm{j} .1468-2370.2012 .00348$

Burnard, Pamela, Anna Craft, Teresa Cremin, Bernadette Duffy, Ruth Hanson, Jean Keene, Lindsay Haynes, and Dawn Burns. 2006. Documenting 'possibility thinking': a journey of collaborative enquiry, International Journal of Early Years Education, 14 (3) 243-262. doi.org/10.1080/09669760600880001

Chappell, Kerry Anne, Tamsin Pender, Elizabeth Swinford, and Katherine Ford. 2016. Making and being made: wise humanising creativity in interdisciplinary early years arts education International Journal of Early Years Education 24 (3) 254-278. doi: 10.1080/09669760.2016.1162704.

Churchill-Dower, Ruth. 2009. 'A Joined Up Future', in Arts Professional. Accessed July 9, 2018 https://www.artsprofessional.co.uk/magazine/feature/joined-future

Cornwall, Andrea, and Rachel Jewkes. 1995. "What is participatory research?" Social Science and Medicine 41 (12):1667-1676. doi: 10.1016/0277-9536(95)00127-S. 
Dahlberg, Gunilla. 2013. 'A dialogue with the co-author of 'the vision of a meeting place', in Peter Moss, editor, Early Childhood and Compulsory Education Reconceptualising the relationship. London: Routledge, 72 - 90.

Dahlberg, Gunilla. and Hillevi Lenz Taguchi. 1994. Förskola och skola -- - om två skilda traditioner och om visionen om en mötesplats [Preschool and school --- two different traditions and the vision of a meeting place]. Stockholm: HLS Förlag.

Department for Schools, Children and Families (DCSF). 2008. Practice Guidance for the Early Years Foundation Stage DCSF Publications: Nottingham.

Department for Education (DfE). 2012. Statutory Framework for the Early Years Foundation Stage Setting the standards for learning, development and care for children from birth to five. London: DfE publications.

Department for Education (DfE). 2013. Elizabeth Truss speaks about 2-year-olds policy and practice. Accessed November 3, 2019 https://www.gov.uk/government/speeches/elizabeth-truss-speaks-about-2-year-oldspolicy-and-practice.

Department for Education (DfE). 2017. Statutory Framework for the Early Years Foundation Stage Setting the standards for learning, development and care for children from birth to five. London: DfE publications. 
Department for Education and Employment (DfEE). 2000. Curriculum Guidance for the Foundation Stage. London: DfEE/SCAA.

Eckhoff, Angela. 2011. Art experiments: introducing an artist-in-residence programme in early childhood education, Early Child Development and Care, 181 (3) 371-385. doi:10.1080/03004430903388089

Edgington, Margaret. 2004. The Nursery Teacher in Action Teaching 3,4 and 5 yearsolds. London: Paul Chapman Publishing.

Gandini, Lella. 2012 The Atelier: A Conversation with Vea Vecchi in The Hundred Languages of Children edited by Carolyn Edwards, Lella Gandini., and George Forman. Norwood: Ablex.

Gattenhof, Sandra. and Mark Radvan. 2009. In the mouth of the imagination: positioning children as co-researchers and co-artists to create a professional children's theatre production, Research in Drama Education: The Journal of Applied Theatre and Performance, 14 (2) 211-224. doi: 10.1080/13569780902868812

Griffin, Shelley. 2017. The fluid infusion of musical culture: embodied experiences in a grade one classroom, Pedagogies: An International Journal, 12 (1) 21-40. doi:10.1080/1554480X.2017.1283993

Lewin, K. 1943. "Defining the 'field at a given time.'." Psychological Review 50 (3):292-310. doi: 10.1037/h0062738. 
McLauchlan, Debra. 2017. Playlinks: a theatre-for-young audiences artist-in-theclassroom project, Pedagogies: An International Journal, 12 (1) 130-142. doi:10.1080/1554480X.2017.1283998

National Advisory Committee on Creative and Cultural Education (NACCCE). 2001. All Our Futures: Creativity, Culture and Education. London: Department for Education and Employment.

Nevanen, Saila, Antti Juvonen, Heikki Ruismäki. 2014. Does Arts Education Develop School Readiness? Teachers' and Artists' Points of View on an Art Education Project, Arts Education Policy Review, 115 (3) 72-81. doi:10.1080/10632913.2014.913970

Nutbrown, Cathy. 2013. Conceptualising arts-based learning in the early years, Research Papers in Education, 28 (2) 239-263. doi: 10.1080/02671522.2011.580365

Paul Hamlyn Foundation (PHF). 2018. Paul Hamlyn Foundation Accessed April 9, 2018 https://www.phf.org.uk/

Petri, Pat. and Helen Chambers. 2010. Richer lives: creative activities in the education and practice of Danish Pedagogues A preliminary study: Report to Arts Council England. London: Institute of Education. Accessed March 30, 2017 http://eprints.ioe.ac.uk/6415/1/Petrie2009Richer\%28Report\%29.pdf 
Remer, Jean. 1996. Beyond Enrichment Building Effective Arts Partnerships with Schools and Your Community New York: American Council for the Arts.

Remer, Jean. 2010. From Lessons Learned to Local Action: Building Your Own Policies for Effective Arts Education in Art Education Policy Review, 11181 -96. doi $10.1080 / 10632911003626879$

Rinaldi, Carlina. 2006. In Dialogue with Reggio Emilia Listening, researching and learning London: Routledge.

Roberts, Paul. 2006. Nurturing Creativity in Young People. A Report to Government to inform Future Policy. London DCMS.

Schon, Donald. 1991. The Reflective Practitioner How Professionals Think in Action. Surrey: Ashgate Publishing Limited.

Swanson, Donald James \& Andrew Shawn Creed. 2014 Sharpening the Focus of Force Field Analysis, Journal of Change Management, 14:1, 28-47.

doi:10.1080/14697017.2013.788052

Vecchi, Vea. 2010. Art and Creativity in Reggio Emilia Exploring the Role and Potential of Ateliers in Early Childhood Education London: Routledge 
Vermeersch, Lode and Anneloes Vandenbroucke. 2013. Schools and cultural organisations. Natural partners in art and cultural education (ACE) Procedia Social and Behavioural Sciences 116:1032-1039. Doi: 10.1016/j.sbspro.2014.01.341

Young, Susan. 2012. The Little Big Bang Report. Accessed April 1, 2017 http://www.takeart.org/images/uploads/downloads/LLBFullreport(USETHIS).pdf

Young, Susan. 2016. Early childhood music education research: An overview Research Studies in Music Education, 38 (1), 9-21. doi: 10.1177/1321103X16640106 
